\title{
Diálogos Brasil-Estados Unidos
}

\section{Entrevista com Barbara Weinstein*}

Entrevistadora: Cecília Azevedo

1. A Sra. é a primeira "brazilianista" e a sétima mulher eleita presidente da prestigiosa e centenária AHA. Esta eleição, sua ida para a New York University e a do Prof. Kenneth Maxwell para Harvard, fundando núcleos de estudos brasileiros nessas renomadas instituições acadêmicas, seriam indicadores de um maior interesse pelos estudos brasileiros nos Estados Unidos?
BW - Duvido que a minha eleição seja um sinal de qualquer tendência maior, mas o fato de Harvard investir num núcleo de estudos brasileiros, e a NYU finalmente retomar a tradição, iniciada pelo saudoso Warren Dean, de estudos brasileiros no Departamento de História talvez sejam indicações de um maior interesse pela História do Brasil e o reconhecimento da dificuldade de sustentar um bom programa de História da América La-

\footnotetext{
* Professora da New York University (NYU), Barbara Weinstein é a atual presidente da AHA (American Historical Association). É também editora da Hispanic Historical American Review, periódico de história latino-americana de maior repercussão nos Estados Unidos. B. Weinstein é autora de diversos livros e artigos publicados tanto nos Estados Unidos quanto no Brasil, onde mantém contato permanente com historiadores brasileiros de diversas instituições desde a década de 1980.
} 
tina sem um "brazilianista" no corpo docente. Mas há dois fatores que continuam limitando o desenvolvimento de estudos brasileiros nos States. Um é a questão da língua: é ainda muito raro um curso de português oferecido no high school, e isto significa que os alunos, ao entrarem na universidade, se mostram mais dispostos a estudar um país de língua espanhola. O segundo fator é a presença nos Estados Unidos de muitos mexicanos, cubanos, dominicanos etc. (natos ou descendentes). Como é totalmente compreensível, estas "minorias" militam em favor de programas que tratam dos países de origem, no contexto de história da América Latina. Claro que hoje há, também, uma comunidade de imigrantes brasileiros, mas esta comunidade continua meio "invisível".

\section{A Sra. estudou, entre outras} questões, a exploração da borracha na Amazônia de meados do século XIX ao início do século XX e a formação do operariado paulista entre 1920 e 1964. Pode contar-nos as razões de ter eleito o Brasil como seu objeto de estudo e, ao longo de sua trajetória, quais foram os autores brasileiros que mais a influenciaram?
BW - No programa de graduação comecei a me interessar pela área de América Latina principalmente por causa da Revolução Cubana. Naquele momento histórico, do movimento contra a guerra no Vietnã e do surgimento de um movimento estudantil esquerdista nos Estados Unidos, o chamado Terceiro Mundo era a região que mais me atraía por ser, do meu ponto de vista, a parte do mundo mais disposta às transformações revolucionárias. A história do Brasil me interessava - nenhuma surpresa nisso - por causa do seu passado de escravidão e presença africana. Mas inicialmente eu não ia ser "brazilianista" - pretendia fazer pesquisa sobre a região do Prata. Apesar de ter estudado com Stanley Stein na graduação e ter feito cursos de português, quando entrei no programa de pós-graduação, minha idéia era trabalhar com a história da Argentina. Tinha lido o famoso livro do E. P. Thompson e minha idéia inicial era fazer uma tese sobre o movimento operário na Argentina, um tema ainda pouco trabalhado em 1973, o ano que comecei os estudos do doutorado. Mas por sorte, entrei em Yale no ano em que Emilia Viotti da Costa chegou lá, e esta coincidência certamente foi o fator mais importante na reorientação dos meus estudos. Foi Emília quem me levou a mudar para a história do Brasil, e 
ela é a historiadora brasileira, tanto pelos trabalhos escritos como pelas suas aulas, que mais me influenciou (e continua me influenciando). Outros autores que li com muito interesse na época foram Florestan Fernandes, Fernando Henrique Cardoso, Otávio Ianni, Carlos Guilherme Mota, Paulo Sérgio Pinheiro e Boris Fausto. E tive a grande sorte de publicar meu primeiro artigo impresso num volume com Maria Lígia Prado e Maria Helena Capelato. Os trabalhos destas duas historiadoras, para não falar da amizade delas, tiveram uma influência enorme na minha carreira.

\section{A Sra. faz parte de uma geração} de "brazilianistas" que viveu os efeitos da ebulição política e social dos anos 1960 e 1970 nos Estados Unidos e da ditadura militar no Brasil. Paradoxalmente muitos historiadores norte-americanos de esquerda que denunciaram a repressão no Brasil e o apoio do governo norte-americano às ditaduras do continente sofreram a rejeição, algumas vezes explícita, de intelectuais de esquerda brasileiros. $\mathrm{O}$ fato de que, naquele contexto, alguns "brazilianistas" tenham tido acesso a arquivos vedados a historiadores brasileiros reforçava temores de que os intelectuais norte-americanos, consciente ou inconscientemente, favorecessem o imperialismo cultural norte-americano. Como atravessou esse momento difícil?

BW - Por ter escolhido estudar a história da Amazônia, fiquei longe dos circuitos principais da intelectualidade brasileira naquela época. Havia uma ou outra pessoa que desconfiava da norte-americana que havia aparecido em Belém do Pará para fazer pesquisa sobre o ciclo da borracha, mas mesmo numa época de muita paranóia, era difícil imaginar que eu tivesse motivos outros além de escrever uma tese de doutorado. Mas isso não quer dizer que o fato de eu ser norte-americana não tivesse sido uma vantagem, mesmo em Belém. Consegui acesso às escrituras públicas do Cartório Chermont, cujo proprietário era deputado estadual pela Arena. Acho que ele abriu as portas do cartório justamente porque eu era norte-americana. Mesmo sabendo que eu era uma pessoa da esquerda, ele gostou da idéia de ter uma "gringa” pesquisando no escritório dele.

\section{Apesar das tensões do período} da ditadura militar, a circulação de obras de sociólogos, antropólogos e historiadores norte-americanos foi muito importante no desenvolvimento das ciências sociais no 
Brasil. Donald Pierson, Richard Morse, Charles Wagley, Thomas Skidmore, entre outros, foram muito influentes. Na última década podemos verificar iniciativas interessantes. O Projeto Resgate identificou a documentação sobre o Brasil depositada em arquivos públicos nos Estados Unidos; publicações, como o Guia de Estudos Brasileiros nos Estados Unidos, organizado por Marshall Eakin e Paulo Roberto de Almeida, e eventos como o recente Seminário promovido pela Casa Rui Barbosa, no Rio de Janeiro, reunindo várias gerações de "brazilianistas" parecem abrir caminhos para pesquisas conjuntas. Como a Sra. avalia esse intercâmbio intelectual?

BW - Acho que esta colaboração já é anterior às iniciativas citadas. Há poucos "brazilianistas" que não passam um semestre ou mais em uma universidade brasileira, e muitos historiadores brasileiros têm feito pós-doutorado ou lecionado em universidades norte-americanas. Ainda mais importante, hoje em dia há poucas divergências - em termos de temas, abordagens, métodos - entre os historiadores norte-americanos e os brasileiros. Claro que os norteamericanos circulam, durante a maior parte da carreira, num meio acadêmi- co diferente e não têm a vantagem de trabalhar num contexto em que a história do Brasil é tão valorizada. Por isso, tendemos a privilegiar temas gênero, raça, escravidão - que despertam o interesse de nossos colegas não "brazilianistas". Mesmo assim, vejo uma convergência marcante entre as preocupações e orientações dos "brazilianistas" e dos brasileiros.

\section{Como a Sra. caracterizaria} a nova geração de "brazilianistas"? Quais seriam os interesses e temas mais freqüentados? Em que medida a história do Brasil tem estimulado reflexões originais ou, dito de outro modo, de que maneira os "brazilianistas" se diferenciariam de outros "latinoamericanistas"?

BW - Os temas mais freqüentados continuam sendo escravidão, emancipação, gênero etc. Além disso, a nova geração está fazendo pesquisas muito intrigantes e inovadoras sobre cultura popular e sobre a vida urbana em geral. Também a história da lei e da criminalidade, e como a lei conforma a sociedade (e não sendo uma mera reflexão dos interesses preexistentes), é um tema central entre os jovens historiadores "brazilianistas". Mas os jovens brasileiros também se interessam por estes temas - outra vez, acho 
difícil hoje distinguir entre os temas preferidos dos "brazilianistas" e dos brasileiros.

\section{Pensando no outro lado da moe-} da... Os estudos norte-americanos, que ainda têm pouca expressão no Brasil, não teriam herdado o mal apontado anteriormente, qual seja, a rejeição indiscriminada a tudo e a todos relacionados aos Estados Unidos, a despeito do seu peso no cenário mundial e particularmente sua influência na história recente do Brasil e da América Latina? A Sra. percebe uma abertura maior dos historiadores norte-americanos para o díálogo com historiadores brasileiros que estudam história norte-americana? A historiografia norte-americana e especialmente o que poderíamos chamar de cultura histórica escolar estariam ainda marcadas por uma perspectiva nacionalista? $\mathrm{O}$ que a AHA poderia fazer no sentido da internacionalização dos estudos norte-americanos?

BW - Claro que o desgosto com a política exterior dos Estados Unidos e o temor da influência norteamericana explicam, em parte, o "subdesenvolvimento" dos estudos norte-americanos no Brasil. Mas há outro aspecto: os historiadores norteamericanos, até recentemente, quase todos abordavam a história dos Estados Unidos como uma história "excepcional", um caso à parte. Não é de se estranhar que os historiadores de fora dos Estados Unidos não conseguissem entrar neste projeto norte-americano de excepcionalismo, nem perceber algo muito interessante nessa historiografia do ponto de vista do pesquisador do exterior. Quanto à AHA, é muito importante notar que ela não é a associação dos historiadores que estudam os Estados Unidos; existe uma organização importante, mas menor, a OAH (Organization of American Historians), que se dedica exclusivamente à história dos Estados Unidos. A AHA é a associação da profissão de história em qualquer área; inclusive o maior grupo de sócios da AHA é composto por historiadores da Europa, e não dos Estados Unidos. Por isso, é muito importante que a AHA se esforce para garantir uma presença internacional significativa nos seus congressos. Ultimamente, a associação duplicou o montante gasto para subvencionar as viagens de historiadores do exterior para o congresso da AHA, mas o dinheiro para este fim continua inadequado. Acho que precisamos conseguir novas verbas especificamente voltadas para facilitar a presença de historiadores 
do exterior, em especial das regiões com menos recursos, como África, Ásia e ainda a América Latina. E os presidentes, na minha opinião, devem fazer um esforço maior para convidar os colegas que trabalham fora dos Estados Unidos. Hoje em dia qualquer historiador bem conhecido nos meios acadêmicos tem ligações com colegas no exterior, e esta rede de contatos pode ser mobilizada para "internacionalizar" o programa do congresso da AHA.

\section{Nos Estados Unidos e no Brasil} a difusão dos estudos culturais, especialmente a afirmação de novos referenciais acadêmicos e políticos ligados a questões étnicas e de gênero, tem gerado intensas reações. Há quem chegue a considerar que a criação de espaços próprios e independentes para estudos dessa natureza responda apenas a interesses e disputas institucionais que geram fragmentação e despolitização dos estudos históricos. Qual a sua avaliação?

BW - Acho que nenhuma tendência dentro da academia responde apenas a disputas pelos recursos sempre limitados no meio universitário. Ao mesmo tempo, acho que isto faz parte de qualquer conflito acadêmico. $\mathrm{Eu}$, por exemplo, não me entusiasmo muito pelo discurso contra as divisões disciplinares tradicionais (história, antrolopogia, filosofia etc.) e em favor dos programas interdisciplinares (estudos culturais) por duas razões. Uma crítica é, vamos dizer, "intelectual": creio que nos programas interdisciplinares muitas vezes vale tudo, faltam critérios, e os alunos acabam estudando as coisas mais diversas sem noção de um método ou de uma abordagem coerente. Há pessoas muito criativas e rigorosas que conseguem fazer um bom trabalho sob estas circunstâncias, mas a maioria não. De outro lado, do ponto de vista mais prático, também não me animo muito com os programas interdisciplinares, porque eles permitem uma "consolidação" do corpo docente que inevitavelmente serve para diminuir o número de empregos acadêmicos. Mas este geralmente não é o caso dos programas de estudo de gênero ou de grupos étnicos. Eles criam novas vagas em áreas tradicionalmente negligenciadas, e num certo momento da história da universidade, eles desempenharam um papel extremamente importante ao impulsionar as mudanças nas disciplinas. O problema é sustentar a qualidade destes programas, que muitas vezes entram em declínio depois de um período inicial de grandes inovações. No entanto, já existe um grupo de professores e alunos 
que tem um investimento pessoal e político na manutenção do programa, e seria extremamente difícil dizer "tudo bem, o programa de Estudos da Mulher/Women's Studies já cumpriu sua missão, todas as disciplinas já reconhecem o valor dos estudos de gênero, e está na hora de terminálo”. Imagine a reação que isto iria provocar! Mas dizer que a reação é motivada apenas pela disputa pelos recursos institucionais é simplificar demais a questão.

8. Haveria alguma relação entre esse debate e os que ocorrem no âmbito político mais amplo, envolvendo concepções sobre cidadania e direitos sociais de imigrantes e minorias raciais? $O$ paradigma do multiculturalismo pode servir para pacificar a história ou expõe mais claramente e potencializa os conflitos?

BW -É impossível dizer exatamente qual o impacto do multiculturalismo no âmbito político ou no mundo de fora da universidade, mas posso indicar as vantagens e os limites do multiculturalismo para a "realidade" norte-americana atual. O multiculturalismo valoriza as diferenças culturais e questiona a preocupação com a assimilação. É um discurso de respeito, dignidade, tolerância, que pelo menos diminui e deslegitima a expressão de preconceitos na esfera pública. Um senador republicano da Virginia, um estado tradicionalmente conservador, não conseguiu se reeleger, em parte por ter chamado um jovem de descendência indiana usando uma palavra racista em público. Isto não é pouca coisa. Por outro lado, o multiculturalismo supõe que todas as culturas tenham igual status na sociedade norte-americana, e que não exista uma cultura hegemônica, o que seguramente não é a verdade; de certa forma, o multiculturalismo contribui para disfarçar as hierarquias culturais dos Estados Unidos. Por isso, podemos presenciar a situação atual na qual as universidades valorizam os estudos étnicos, comemorando o mês da cultura latina, o mês da história afro-americana etc., etc., enquanto na sociedade, fora da universidade, é ainda muito fácil para quem está contra a imigração mobilizar um discurso de diferença, da suposta incapacidade dos latinos para plena assimilação, como uma arma nesta disputa política. Este gap entre as práticas nas universidades e na sociedade em geral é algo muito problemático, especialmente hoje em dia, com a campanha contra os imigrantes não documentados (que inevitavelmente repercute em toda a população latina no país), e a tendência de ver qualquer 
pessoa do Oriente Médio, cidadão ou não, como um possível terrorista.

9. Os estudos ou teorias denominados pós-coloniais têm ganhado destaque nos últimos anos, firmando-se as idéias de interação e negociação entre os diferentes atores internacionais, a despeito da disparidade de poder entre eles. Decorrente disso, defendese a adoção de uma perspectiva transnacional e a busca de articulações entre local e global e entre as esferas econômica, política e cultural, valorizando-se, ao lado das relações diplomáticas formais, relações informais envolvendo atores não governamentais. Tal abordagem enfatiza a importância de ir além da dicotomia dominação $\mathrm{X}$ resistência, recuperando a construção de redes e identidades imprevistas. Que polêmicas essa perspectiva tem gerado entre "latino-americanistas" ou interessados nas relações interamericanas?

BW - Não diria que esta nova abordagem tenha gerado polêmicas. A minha impressão é de que não existe nenhum grupo nos Estados Unidos que está fortemente contra ela. Os acadêmicos que fazem história diplomática tradicional não ligam muito para esta nova tendência. Para eles, a história das relações externas continua sendo uma questão de correspondência entre diplomatas, discursos dos representantes governamentais etc. A idéia de privilegiar os intercâmbios informais e culturais está totalmente fora dos seus conceitos da matéria, e este tipo de divergência geralmente resulta numa falta total de diálogo, em vez de uma polêmica. Se existir uma facção acadêmica que discorde desta abordagem, parece-me que está na América Latina, onde a idéia de imperialismo cultural ainda está muito forte e onde há historiadores que certamente acreditam que esta nova linha tende a disfarçar ou subestimar a dominação e a opressão norte-americana. Isto certamente não é a intenção dos historiadores desta linha, mas o questionamento do binômio Estados Unidos/América Latina (hegemônica/subalterna) dificulta uma análise histórica que situe a América do Norte como a vilã do pedaço.

10. Para encerrar, que novas tendências a Sra. identifica na historiografia norte-americana?

BW - Certos temas continuam sendo muito valorizados - a história cultural, história do gênero e da sexualidade, a construção de identidades raciais, 
inclusive a "brancura" (whiteness). Há cada vez mais interesse nos fontes "visuais" - arte, filme, fotos - e na história da música e na cultura popular em geral. A história transnacional é muito badalada, até entre especialistas na história dos Estados Unidos, e a história mundial vai crescendo. Ao mesmo tempo, a micro-história continua forte no meio acadêmico norte-americano. Ultimamente, e por motivos óbvios, os historiadores estão levando mais a sério a questão da religião. Do mesmo modo, há um interesse renovado por questões de imigração e cidadania. Vale a pena citar as áreas que estão em declínio: a história econômica, a história diplomática e a história social (pelo menos aquela que trata dos movimentos de classe). Vários historiadores que trabalham nestas áreas se sentem totalmente marginalizados dentro da profissão. Uma das finalidades da AHA é assegurar um espaço na profissão de história para quem continua fazendo um tipo de história que já saiu de moda. 